\title{
Controlling of Segregation in Rotating Drums by Independent End Wall Rotations ${ }^{\dagger}$
}

\author{
Hsiu-Po Kuo*, Wei-Ting Tseng and An-Ni Huang \\ ${ }^{1}$ Department of Chemical and Materials Engineering, Chang Gung University, Taiwan
}

\begin{abstract}
We present in this study that particle segregation in rotating drums can be controlled by end wall rotations. While the end wall rotational speed dominates the time required for reaching the steady state, the rotational direction of the end walls determines the segregation patterns and the shearing zone size. New segregation patterns with two well-mixed regions close to the end walls are observed in the drums with the end wall rotates in the direction opposite to the cylindrical wall. The end wall rotation causes the formation of the local valley and hill next to the wall. Particles flow into the valley and down the hill causing the formation of the convective flow cell at bed surface. It is the difference of the axial velocities between the large particles and small particles close to the end walls separating the particles of difference sizes in the axial direction. The controlling of the end wall roughness and rotating directions effectively enlarge the size of the end wall shearing zone; resulting segregation patterns which are different from the previous simple segregation band patterns.
\end{abstract}

Keywords: rotating drum, segregation, mixing, end wall rotation, spatio-tempral diagram

\section{Introduction}

Particulate systems in most processes usually consist of components of different physical properties. These properties include sizes, densities, shapes, surface roughness, elasticity and etc. During the particle processing, differences in the particle physical properties may cause segregation, the phenomenon by which particles of similar properties separate into their individual components (Huang and Kuo, 2014). Although size-induced segregation (Klisiewicz et al., 2015), density-induced segregation (Oshitani et al., 2013), elasticity-induced segregation (Kuo et al., 2006a) and surface stickiness-induced segregation (Troiano et al., 2014) have been studied, the underlying physics of such a unique granular segregation phenomenon remains incompletely understood still now (Windows-Yule and Parker, 2015).

Rotating drums, showing rich granular behavior, widely used in industry for mixing, drying, agglomeration, calcinations, cooling and roasting are commonly used to study granular flows and/or particle segregation (Abouzeid and Fuerstenau, 2010; Grajales et al., 2012;

Received 29 May 2015; Accepted 8 June 2015

J-STAGE Advance published online 30 June 2015

1 No. 259, Wenhua 1st Road, Guishan District, Taoyuan City 33302, Taiwan

* Corresponding author: Hsiu-Po Kuo;

E-mail: hpkuo@mail.cgu.edu.tw

TEL: +886-3-2118800 ext 5488 FAX: +886-3-2118668
Dhawan et al., 2014). Studies of particles segregation in rotating drums have long history since 1939 (Oyama, 1939). Researchers used particles of different sizes, masses, densities, shapes and elasticities to experimentally investigate segregation in dry rotating drums (Kuo et al., 2006a; Arntz et al., 2014) or in drums with different interstitial fluids (Chou et al., 2010). Numerically studies of particle flows/segregation in rotating drums are also conducted by a number of groups using DEM and CFD (Marigo et al., 2012; Huang et al., 2013a; Alizadeh et al., 2014; Marigo and Stitt, 2015). Segregation structures have been reported three-dimensionally using MRI and the freeze-slicing method (Kawaguchi et al., 2006; Sederman et al., 2007; Huang and Kuo, 2012). Although other complex segregation patterns have been reported in high fill level drums (Kuo et al., 2006b), particle segregation in rotating drums generally consist of a radial segregation core and segregation bands in the axial direction. The intensity of segregation is affected by the physical properties of the materials and by the drum operating parameters (Huang and Kuo, 2011).

A reasonable level of understanding of the segregation processes within a bidisperse rotating drum system has been achieved. Small particles are wrapped by large particles in the radial direction after several revolutions by the particle percolation mechanism and balancing between the centrifugal and the gravitational forces. Alternative small-particle-rich and large-particle-rich bands in the axial direction are then observed later at the bed 
sdiffack (Turner and Nakagawa, 2000; Maneval et al., 2005; Alizadeh et al., 2013). Comparing to the level of comprehension of the radial segregation cores, our knowledge to the axial segregation bands is poor. Controversially formation mechanisms of the axial segregation bands in the rotating drums have been reported, including the Stochastic diffusion model (Fan and Shin, 1979), the difference of the static/dynamic angle of repose induced diffusional model (Hill and Kakalios, 1994, 1995), the core-thickening model (Khan et al., 2004), and the end wall shearing induced local percolation theory (Kuo et al., 2005). Although most of these models reasonably explain the evolution of the axial segregation bands, the fact that the segregation bands originating close to the two end walls is not satisfactory explained.

Nakagawa is probably the first person who pointed out the importance of the end walls in axial segregation band formation (Nakagawa, 1994). The angle of repose of the particles next to the end wall is different to that in the bulk and particle motion in the axial direction accelerates, causing the formation of the segregation bands. Related reports focused on the influences of the end wall roughness on particle flow/segregation in rotating drums (Maneval et al., 2005; Arntz et al., 2013; Chand et al., 2012). End wall roughening increases the rate of axial segregation and reduces the particle near-wall transverse speed. The change of the frictional force between the end walls and the particles by end wall roughness alters the numbers of the axial segregation bands. A specially designed rotating drum with two independent rotating end walls has been used to improve the comprehension of the role of end wall on the segregation dynamics (Huang et al., 2013b). The central segregation bands were initiated where the end wall shearing was higher.

Understanding and controlling of particle segregation by the end walls has not yet been successful. In this work, the rotating drum with two end walls rotating in the same direction or in the opposite direction to that of the cylindrical wall is used to improve our understanding and to control segregation in rotating drums. The design of the drum and the operating conditions are shown in section 2 . The influence of the end wall rotation on particle segregation and the controlling of particle segregation by end wall rotation are in section 3. Finally, we summarize our major findings and conclusions arising from this study in section 4 .

\section{Experimental details}

The experimental set-up is a rotating drum of $98 \mathrm{~mm}$ inner diameter and $138 \mathrm{~mm}$ length. The drum consists of a Perspex cylindrical wall and the two end walls which rotate independently to the cylindrical wall. Two end wall roughness are investigated: PSS, in which end wall surface is polish stainless steel, and \#220, in which \#220 sand paper (i.e., $220 \mathrm{~mm} \times 220 \mathrm{~mm}, 68 \mu \mathrm{m}$ diameter sand particles per square inch) is glued on the surface of the end walls. The frictional angles of the end walls with different roughness are measured. The frictional coefficients between the particles used in this study and PSS end wall, and the \#220 end wall are 0.47 and 0.57 , respectively. While the cylindrical column rotational speed is set as $10 \mathrm{rpm}$, which corresponds to a tip speed of $0.05 \mathrm{~m} / \mathrm{s}$, the rotational speed of the end wall is $5 \mathrm{rpm}, 10 \mathrm{rpm}, 15 \mathrm{rpm}$, $30 \mathrm{rpm}, 50 \mathrm{rpm}, 70 \mathrm{rpm}$, or $90 \mathrm{rpm}$. In our experiments, two end wall rotational directions are studied: $\mathrm{S}$, in which the rotational direction of the end wall is the same as that of the cylindrical wall, and $\mathrm{O}$, in which the rotational direction of the end wall is opposite to that of the cylindrical wall. The schematic drawing of the experimental set-up is shown in Fig. 1.

Particle segregation is investigated in a bidisperse system using two species of glass particles (density = $2510 \mathrm{~kg} \mathrm{~m}^{-3}$ ), each of equal physical properties but differing in their sizes and colors. The large particles are black and within the sieving size range of $1.19 \mathrm{~mm}-1.41 \mathrm{~mm}$. The small particles are white and within the sieving size range of $0.81 \mathrm{~mm}-1.00 \mathrm{~mm}$. The large and small particles are only different in colors and sizes. The dynamic angles of repose of small and large particles in the $10 \mathrm{rpm}$ PSS rotating drum are $24^{\circ}$ and $27^{\circ}$, respectively. The relatively large size of the particles and the materials used in this study allow us to neglect the triboelectric effects within the system.

In a typical segregation experiment, $20 \%$ of the drum volume is firstly filled by large particles. Small particles are then placed on top of the large particles and the total
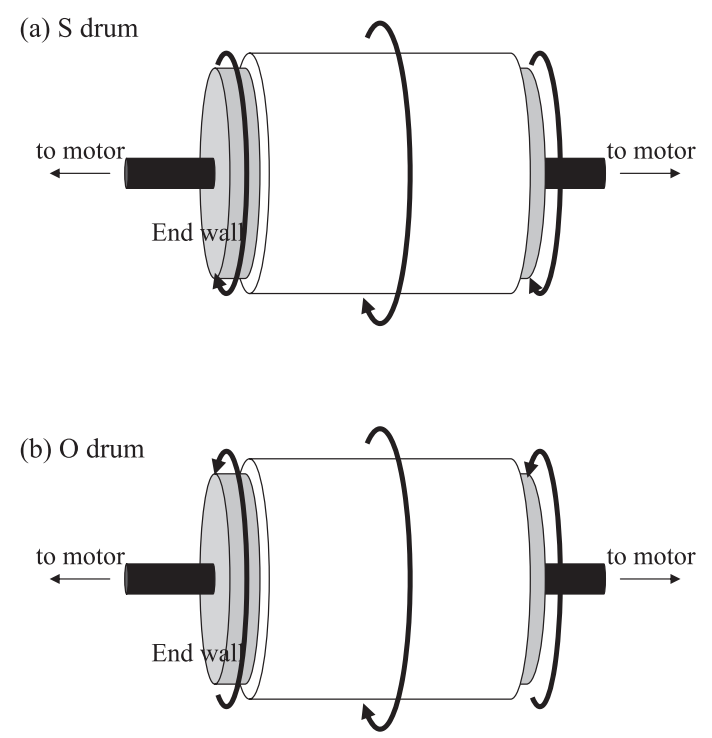

Fig. 1 Schematic drawings of the (a) S drum and (b) O drum. 
an $a^{0}$ or.

letel is set as $40 \%$. Two motors independently control the rotational speeds/directions of the cylindrical wall and the end walls. Two motors start at the same time and the bed surface is simultaneously recorded by a video camera (1 fps, HDR XR-520, Sony, Japan) for $60 \mathrm{~min}$ and by a high speed camera (300 fps, MotionPro-Y3, Nikon, Japan) for $5 \mathrm{~s}$. The lightings are adjusted to show the best color contrast between the two species.

The trajectories of the tracer particles are recorded by the MotionPro-Y3 high speed camera and the Particle Imaging Velocimetry (PIV) technique is used to visualize the flow patterns at the bed surface (Chung et al., 2010). The tracer particles are identical to the particles used in the segregation experiments but differing in their colors. The cell size for flow pattern visualization is $2.4 \mathrm{~mm} \times 2.4 \mathrm{~mm}$.

The development and long lasting instabilities of the bed surface segregation patterns are studied by the spatio-tempral diagrams (Caps et al., 2003). Here, the spatio-tempral diagrams are prepared by stacking 3600300 pixel $(\mathrm{W}) \times 1$ pixel $(\mathrm{H})$ video camera images. The colors of the spatio-tempral diagrams are in gray-scale. The color calibration confirms that the large black particle show a gray-scale color less than 80 . The large black particle concentrations in the near-wall region (i.e., within $2 \mathrm{~cm}$ next to the end walls) is approximated by the fractions of the black pixels in the left-most 43 pixel $(\mathrm{W}) \times 3600$ pixel $(\mathrm{H})$ area and in the right-most 43 pixel $(\mathrm{W}) \times 3600$ pixel $(\mathrm{H})$ area in the spatio-tempral diagrams.

\section{Results and discussion}

The bed surface spatio-tempral diagrams of the drums operating at different conditions are shown in Fig. 2. The end walls of the drums in Fig. 2(a) and Fig. 2(b) are PSS and $\# 220$, respectively.

Symmetric segregation patterns are observed after a relatively long operation time since the two end walls rotate in the same direction and at the same speed. The spatio-tempral diagrams represent the development of the segregation patterns. While the end wall rotational speed dominates the time required for reaching the steady state, the rotational direction of the end walls determines the segregation patterns. In S drums, the segregation pattern is characterized by two separating small-particle-rich white bands at two sides of the drum. In $\mathrm{O}$ drums, the segregation pattern is characterized by one small-particle-rich white band at the central of the drum. At the same rotational time, the color of the small-particle-rich white band turns grayer when the rotational speed of the end wall increases, indicating the increasing of the amount of the black large particles onto the small-particle-rich white bands.

In $\mathrm{O}$ drums, the local mixing at steady state is good

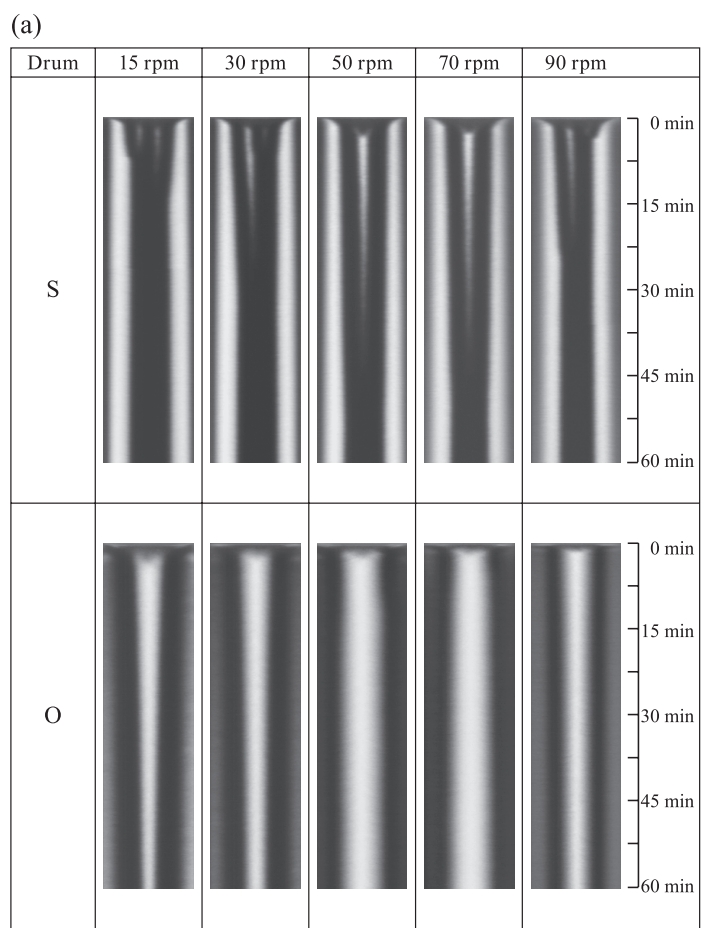

(b)

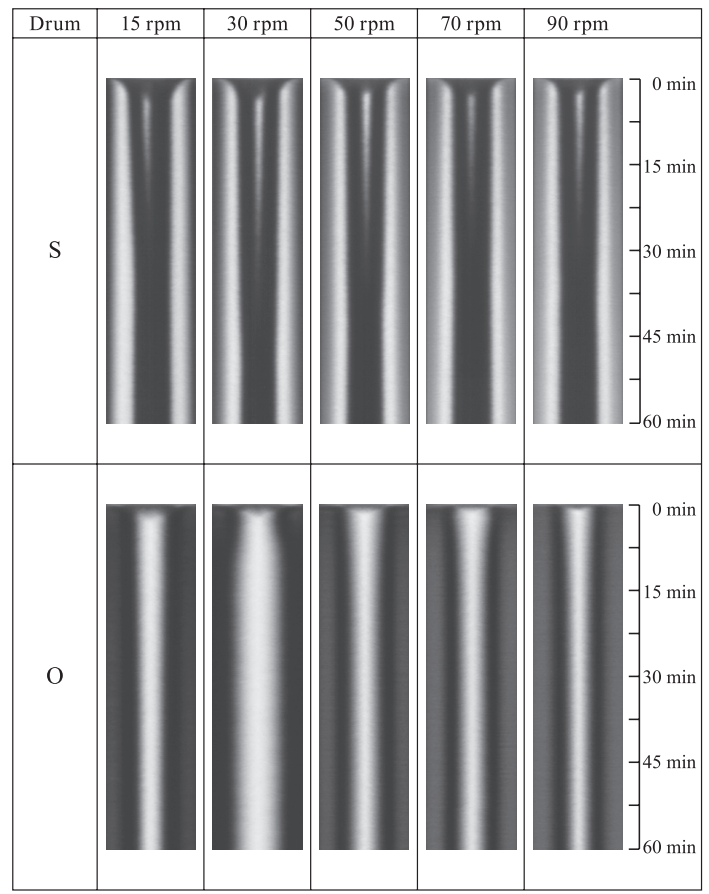

Fig. 2 The spatio-tempral diagrams of the segregation patterns in the drums rotating at different end wall speeds: (a) PSS and (b) \#220 end walls.

and the comparisons between different rotational speeds are neglected. The local mixing in the near end wall region (say $2 \mathrm{~cm}$ next to the end wall) as a function of the end wall rotational speed is analyzed in $\mathrm{S}$ drums. The fractions of the large black particle pixels at steady state (i.e., the last $200 \mathrm{~s}$ in Fig. 2) are calculated and the results are shown in Fig. 3. As the rotational speed of the end 


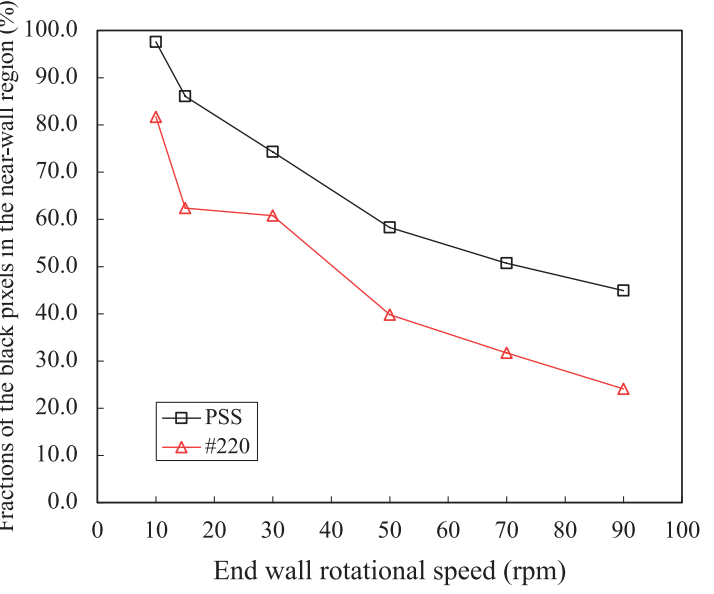

Fig. 3 The fractions of the black pixels in the next to wall region at steady state as a function of the end wall rotational speed in $\mathrm{S}$ drums. walls increases, the number of the small white particles in the near end wall large-black-particle-rich band increases, causing the decreasing of the fraction of the black pixels in the next to wall region. The fraction of the black pixels in the next to the end wall region at steady state is lower when the end wall surface is rougher $\# 220$. The end wall roughness enhances local mixing in the region next to the end walls in $\mathrm{S}$ drums.

The small white particles migrate from the center of the drum to two end walls in S drums in Fig. 2, causing the disappearance of the (central) small-white-particle-rich segregation band and an increasing of the width of the white-particle-rich segregation bands at two sides. While the widths of the steady state white-particle-rich segregation bands at two sides are similar in all cases in $\mathrm{S}$ drums, the width of the steady state central white-particle-rich

(a)

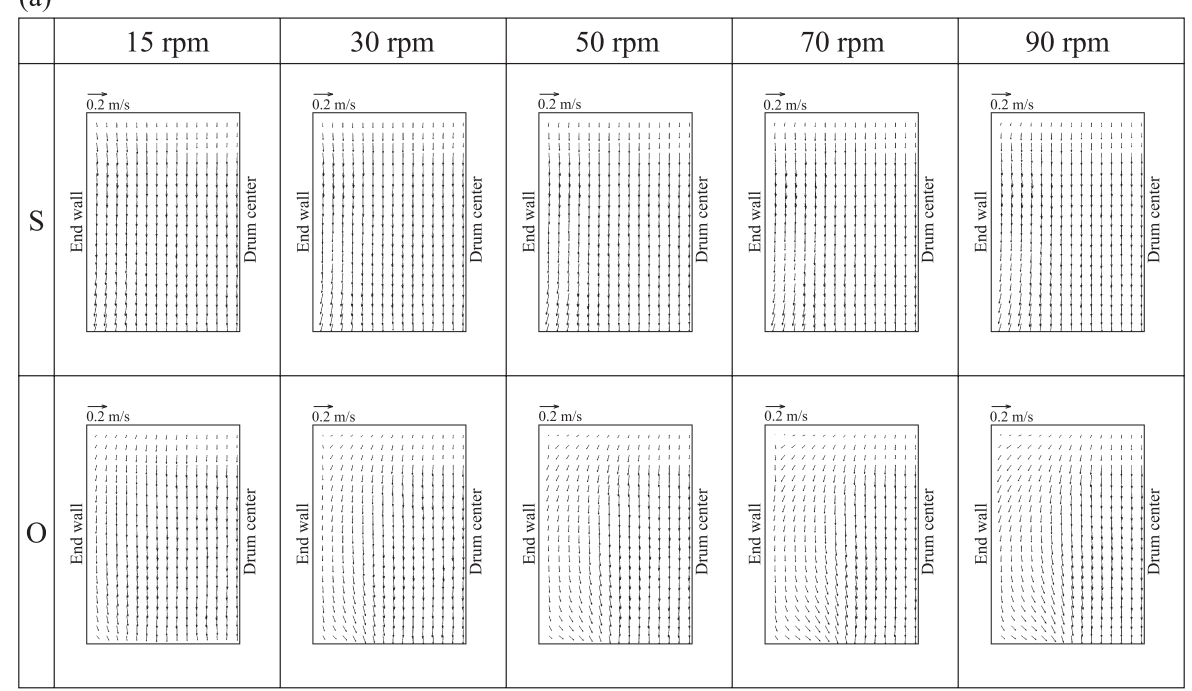

(b)

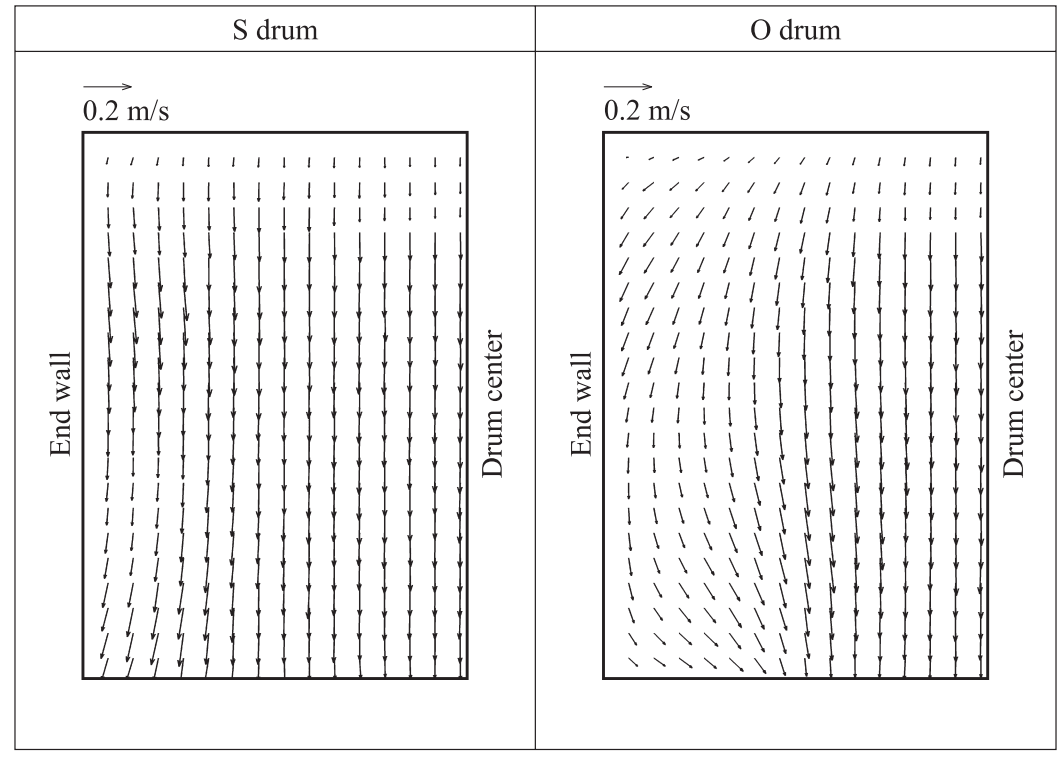

Fig. 4 (a) Large particle PIV flow patterns in the left-hand side of the drum fitted with PSS end walls. (b) The enlargement of $90 \mathrm{rpm}$ cases. 
segregation band in $\mathrm{O}$ drums is a function of the end wall rorational speed. It is interesting to note that the largest central band width at steady state occurs at $70 \mathrm{rpm}$ in $\mathrm{O}$ drums with PSS end walls and at $30 \mathrm{rpm}$ in $\mathrm{O}$ drums with \#220 end walls. Although the existence of the maximum steady state central band width has been reported (Huang et al., 2013b), its dependence on the end wall rotational speed and roughness is initially reported.

The large particle PIV velocity profiles at the bed surface in the left-hand side of the drum with PSS end walls are shown in Fig. 4(a) and the enlargements of $90 \mathrm{rpm}$ cases are shown in Fig. 4(b). The motion of the particles close to the end walls is affected by the end wall rotation. Depending on their positions, the particles may be pushed inside the bed by the end wall rotation, forming a local valley next to the wall, or they may be pushed outside the bed by the end wall rotation, forming a local hill next to the wall.

The direction of the end wall rotation determines positions of the local valley and the local hill and hence the direction of the convective flow cell. The flows of the particles into the valley and down the hill cause the axial motion of the particles and the formation of the convective flow cell observed in Fig. 4. In O drums, while the particles at the upper half of the bed surface fall into the valley and move towards the end walls, the particles at the lower half of the bed surface flow down the hill and move towards to the center of the drum.

Axial velocities of the large and small particles in $\mathrm{S}$ drums with PSS end walls and in O drum with PSS end walls are shown in Fig. 5 and Fig. 6, respectively. The values of the particle axial velocity just next to the end walls are not shown here due to the limitations of the resolution of the camera. The influence of the end wall rotational speed on the particle axial velocity is more pronounced in $\mathrm{O}$ drums. The large and small particles located to the region next to the end walls are both dragged up to the local hill by the rotation of the end walls to about the same height. The local hills are in the upper $1 / 3$ of the bed surface close to the end walls in $\mathrm{S}$ drums and in the lower $1 / 3$ of the bed surface close to the end walls in $\mathrm{O}$ drums. Since the large particles experienced greater inertia than the small particles, when the particles fall down from the local hills, the large particles show greater downslope axial velocities than the small particles in Fig. 5(a) and Fig. 5(b) and in Fig. 6(c) and Fig. 6(d).

The differences between the axial velocities of the small and large particles in rotating drums with PSS end walls are shown in Fig. 7. The differences between the axial velocities of the small and large particles are greater in $\mathrm{O}$ drums than those in $\mathrm{S}$ drums. We show direct evidence that it is the difference of the axial velocities between the large particles and small particles close to the end walls causing the separation of the particles in the (a)

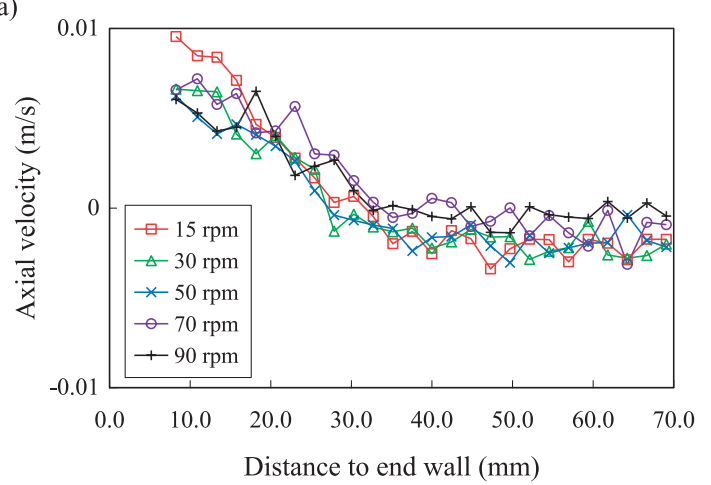

(b)

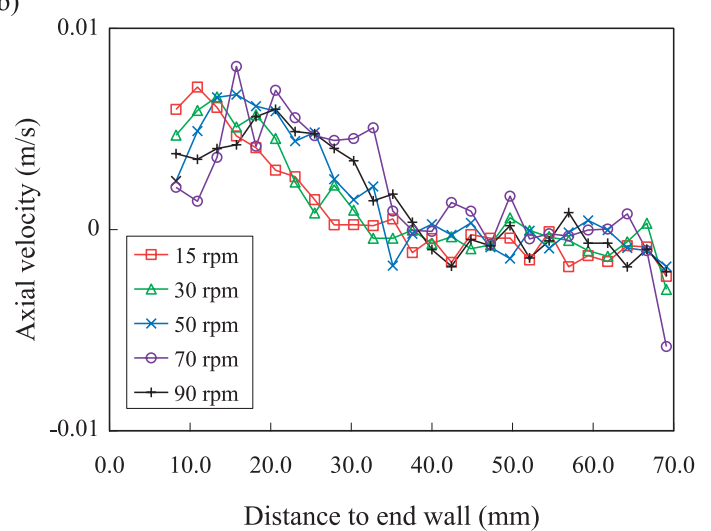

(c)

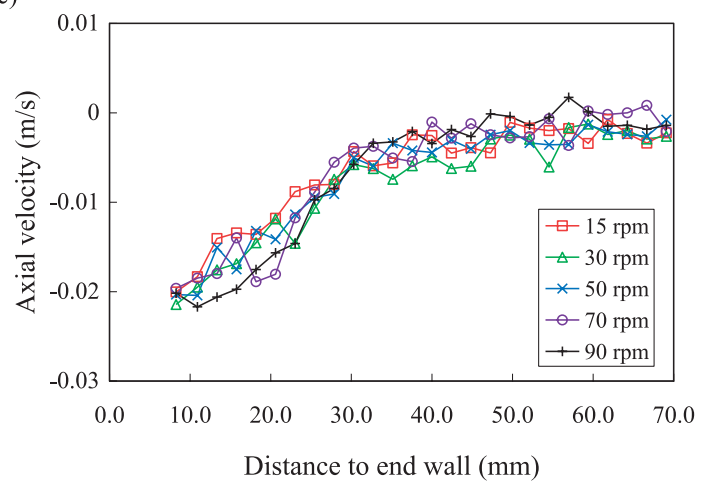

(d)

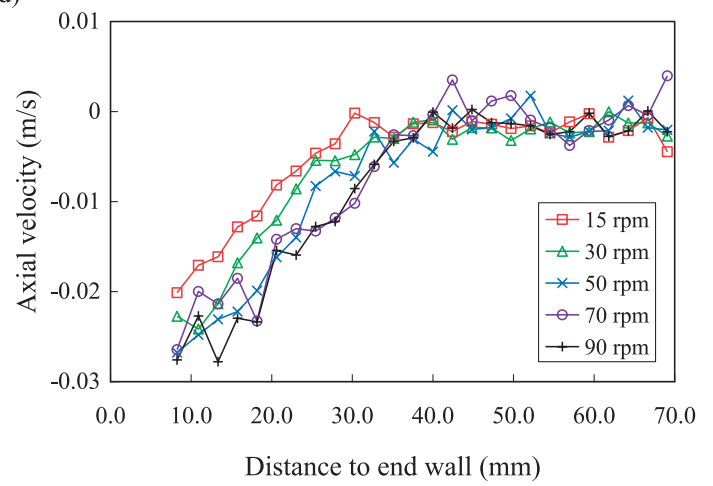

Fig. 5 Axial velocities of (a) large particles in the upper 1/3 of bed surface, (b) small particles in the upper $1 / 3$ of bed surface, (c) large particles in the lower $1 / 3$ of bed surface, and (d) small particles in the lower $1 / 3$ of bed surface in S drums with PSS end walls. 


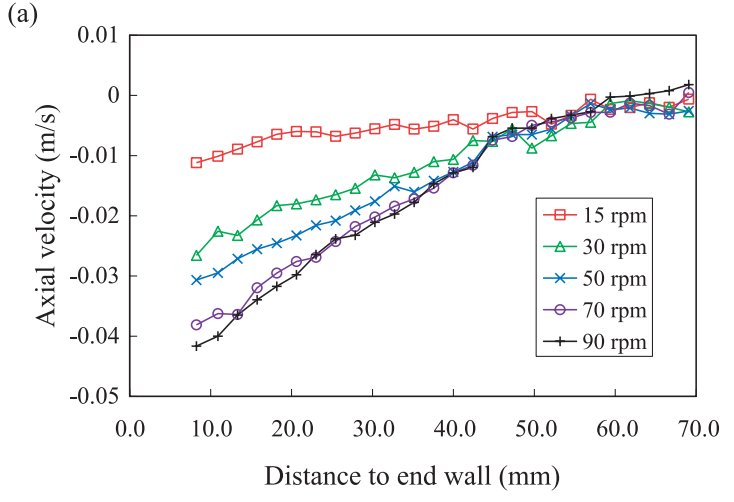

(b)

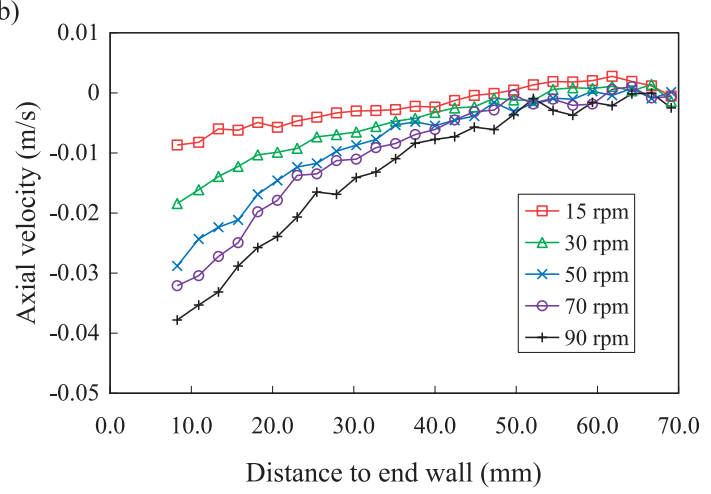

(c)

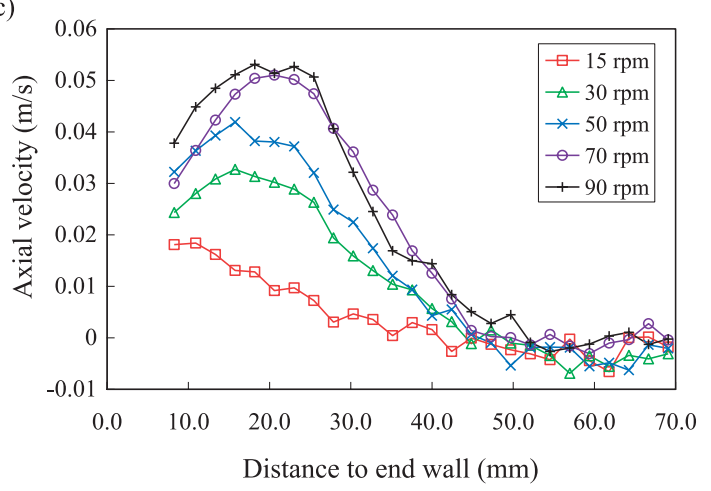

(d)

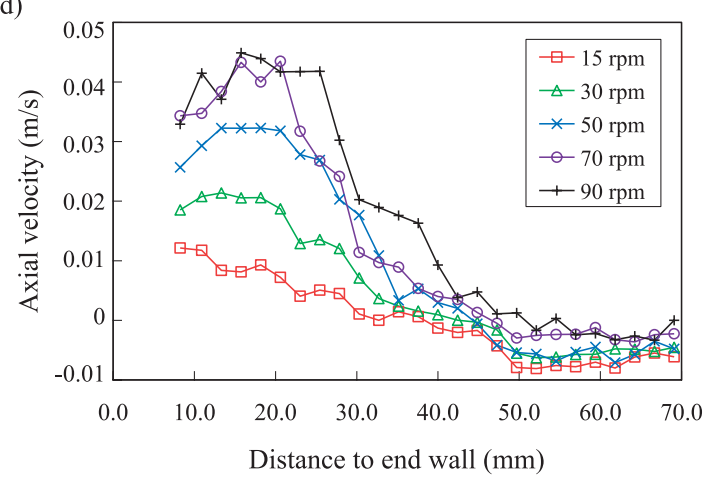

Fig. 6 Axial velocities of (a) large particles in the upper $1 / 3$ of bed surface, (b) small particles in the upper $1 / 3$ of bed surface, (c) large particles in the lower $1 / 3$ of bed surface, and (d) small particles in the lower $1 / 3$ of bed surface in $\mathrm{O}$ drums with PSS end walls. (a)

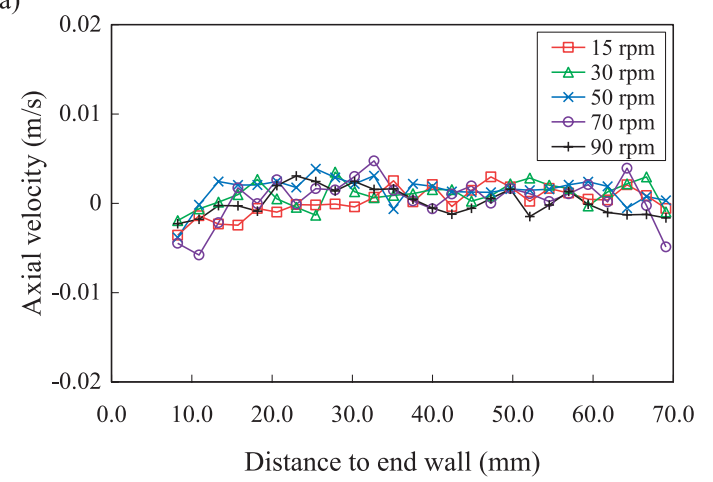

(b)

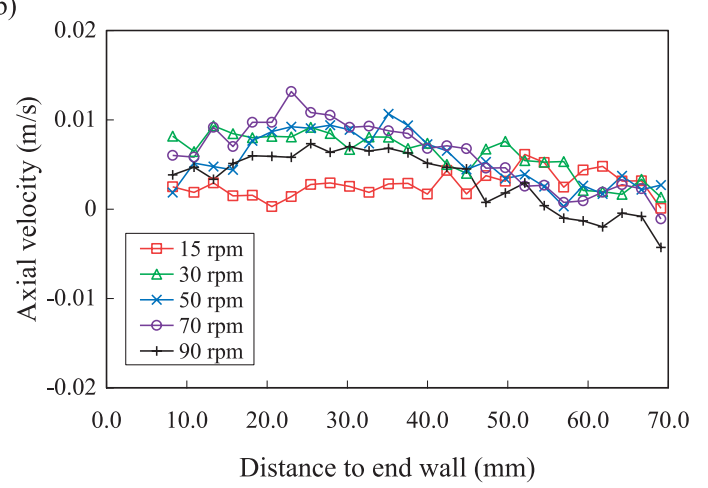

(c)

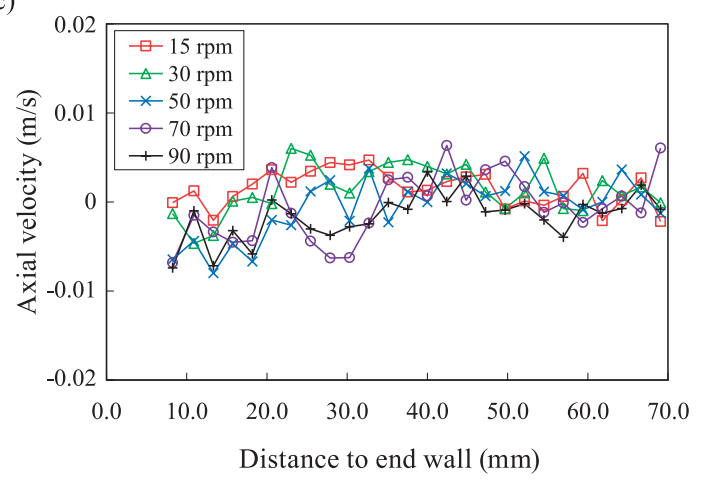

(d)

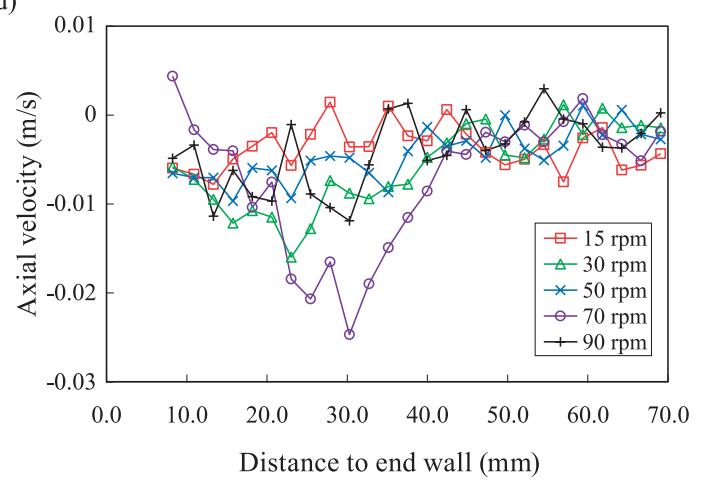

Fig. 7 The difference of the particle axial velocities between small particles and large particles in the (a) upper $1 / 3$ of the bed surface in S drums, (b) upper 1/3 of the bed surface in $\mathrm{O}$ drums, (c) lower $1 / 3$ of the bed surface in $\mathrm{S}$ drums, and (d) lower $1 / 3$ of the bed surface in $\mathrm{O}$ drums with PSS end walls. 
(a)

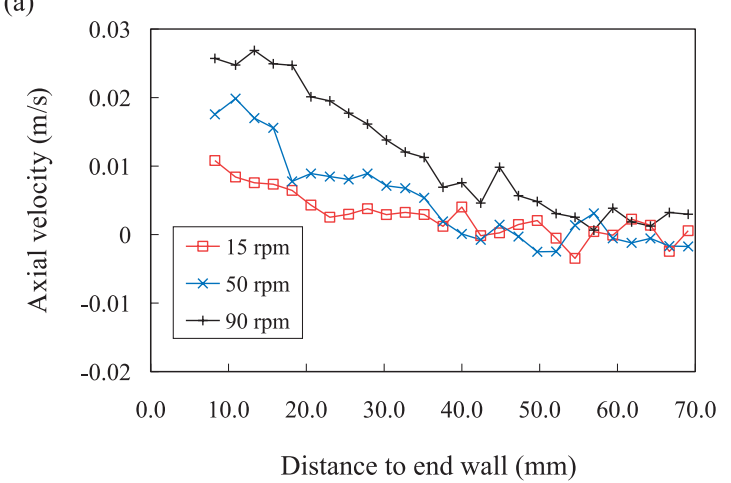

(b)

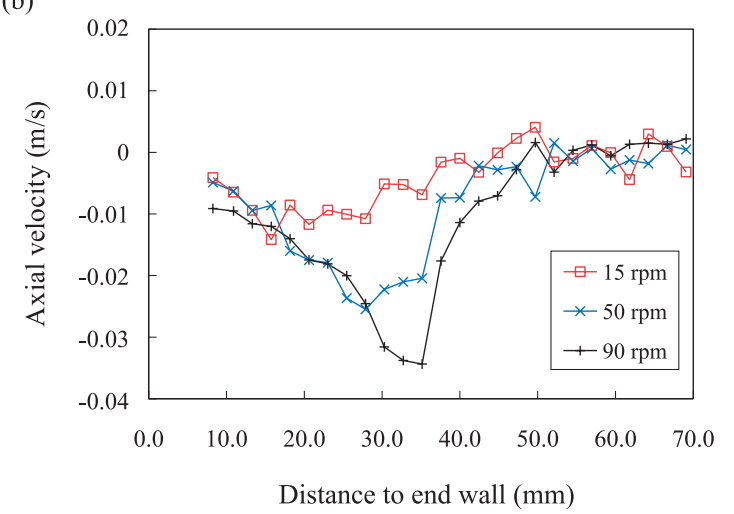

(c)

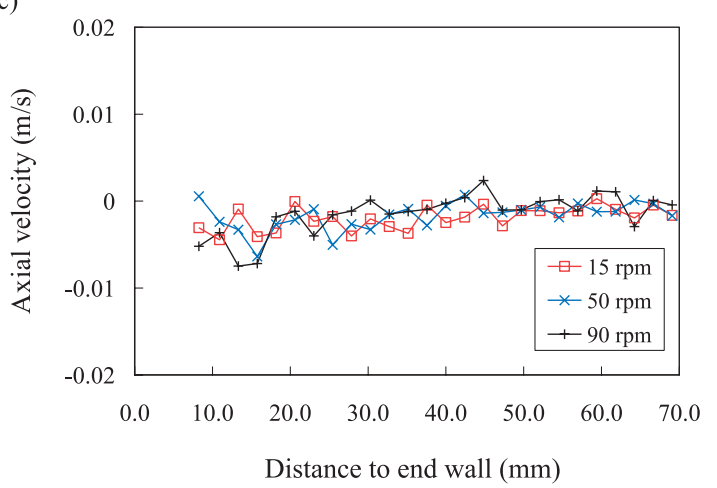

(d)

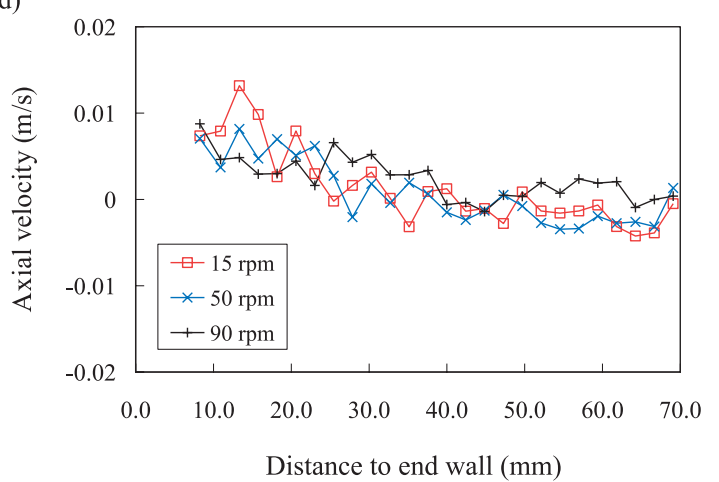

Fig. 9 The differences of the large particle axial velocities in the drums with PSS end walls and those in the drums with \#220 end walls: (a) in the upper $1 / 3$ of bed surface in $\mathrm{O}$ drums, (b) in the lower $1 / 3$ of bed surface in $\mathrm{O}$ drums, (c) in the upper $1 / 3$ of bed surface in $S$ drums, and (d) in the lower $1 / 3$ of bed surface in $S$ drums. 
partiches in drums with different end wall roughnesses and shown in Fig. 9. Only three rotational speeds are presented here to ease the comparisons.

The differences are observed in the shearing zones only and are greater in $\mathrm{O}$ drums than in $\mathrm{S}$ drums. Since the influence of the end wall surface roughness on particle axial motion is not significant in S rums, previous researchers who studied the influence of the end wall roughness on segregation patterns in rotating drums did not observed new segregation patterns as those shown in Fig. 2. The dual effects of the end wall roughness and rotational speeds in $\mathrm{O}$ drums noticeably change the particle axial velocities. New segregation patterns with two quite well mixed regions close to the end walls shown in $\mathrm{O}$ drums are thus observed in Fig. 2.

\section{Conclusions}

An original rotating drum is used to study the effects of the end wall rotation/shearing on particle segregation in rotating drums. The rotational direction of the end walls determines the segregation patterns and new segregation patterns with two well-mixed regions close to the end walls are initially observed in $\mathrm{O}$ drums. The end wall roughness enhances local mixing in the region next to the end walls in $\mathrm{S}$ drums. There exists a maximum central band width at steady state in $\mathrm{O}$ drums: at $70 \mathrm{rpm}$ while using polished stainless steel end walls and at $30 \mathrm{rpm}$ while using \#220 sand paper end walls. The end wall rotation causes the formation of the local valley and hill next to the wall. Particles flow into the valley and down the hill cause the formation of the convective flow cell at bed surface. The influence of the end wall rotational speed on the particle axial velocity is more pronounced in $\mathrm{O}$ drums. The difference of the axial velocities between the large particles and small particles close to the end walls causing the separation of the particles in the axial direction. The dual effects of the end wall roughness and rotational speeds in $\mathrm{O}$ drums noticeably change the particle axial velocities. The controlling of the end wall rotational speed and direction effectively enlarge the size of the end wall shearing zone.

\section{Acknowledgements}

The authors are grateful for the financial support from Ministry of Science and Technology, Taiwan (MOST 1032221-E-182-068) and Chang Gung Memorial Hospital (BMRP 634). We would also like to gratefully acknowledge Professor S.S. Hsiau at National Central University, Taiwan for his help in the PIV measurements.

\section{References}

Abouzeid A.-Z.M., Fuerstenau D.W., Flow of non-homogeneous particulates in rotating drums, KONA Powder and Particle Journal, 28 (2010) 155-166.

Alizadeh E., Bertrand F., Chaouki J., Comparison of DEM results and lagrangian experimental data for the flow and mixing of granules in a rotating drum, AIChE Journal, 60 (2014) 60-75.

Alizadeh E., Dubé O., Bertrand F., Chaouki J., Characterization of mixing and size segregation in a rotating drum by a particle tracking method, AIChE Journal, 59 (2013) 18941905.

Arntz M.M.H.D., Beeftink H.H., den Otter W.K., Briels W.J., Boom R.M., Segregation of granular particles by mass, radius, and density in a horizontal rotating drum, AIChE Journal, 60 (2014) 50-59.

Arntz M.M.H.D., Den Otter W.K., Beeftink H.H., Boom R.M., Briels W.J., The influence of end walls on the segregation pattern in a horizontal rotating drum, Granular Matter, 15 (2013) 25-38.

Caps H., Michel R., Lecocq N., Vandewalle N., Long lasting instabilities in granular mixtures, Physica A, 326 (2003) 313-321.

Chand R., Khaskheli M.A., Qadir A., Ge B., Shi Q., Discrete particle simulation of radial segregation in horizontally rotating drum: Effects of drum-length and non-rotating end-plates, Physica A: Statistical Mechanics and its Applications, 391 (2012) 4590-4596.

Chou S.H., Liao C.C., Hsiau S.S., An experimental study on the effect of liquid content and viscosity on particle segregation in a rotating drum, Powder Technology, 201 (2010) 266272.

Chung Y.C., Hsiau S.S., Liao H.H., Ooi J.Y., An improved PTV technique to evaluate the velocity field of non-spherical particles, Powder Technology, 202 (2010) 151-161.

Dhawan N., Rashidi S., Rajamani R.K., Population balance model for crushed ore agglomeration for heap leach operations, KONA Powder and Particle Journal, 31 (2014) 200213.

Fan L.T., Shin S.H., Stochastic diffusion model of non-ideal mixing in a horizontal drum mixer, Chemical Engineering Science, 34 (1979) 811-820.

Grajales L.M., Xavier N.M., Henrique J.P., Thoméo J.C., Mixing and motion of rice particles in a rotating drum, Powder Technology, 222 (2012) 167-175.

Hill K.M., Kakalios J., Reversible axial segregation of binary mixtures of granular materials, Physical Review E, 49 (1994), R3610-R3613.

Hill K.M., Kakalios J., Reversible axial segregation of rotating granular media, Physical Review E, 52 (1995) 4393-4400.

Huang A.N., Kao W.C., Kuo H.P., Numerical studies of particle segregation in a rotating drum based on Eulerian continuum approach, Advanced Powder Technology, 24 (2013a) 364-372.

Huang A.N., Kuo H.P., A study on the transition between neighbouring drum segregated bands and its application to functionally graded material production, Powder Technology, 
de 21292011$) 348-353$.

Hualng A.N., Kuo H.P., A study of the three-dimensional particle size segregation structure in a rotating drum, AIChE Journal, 58 (2012) 1076-1083.

Huang A.N., Kuo H.P., Developments in the tools for the investigation of mixing in particulate systems-A review, Advanced Powder Technology, 25 (2014) 163-173.

Huang A.N., Liu L.C., Kuo H.P., The role of end wall shearing in the drum segregation band formation, Powder Technology, 239 (2013b) 98-104.

Kawaguchi T., Tsutsumi K., Tsuji Y., MRI measurement of granular motion in a rotating drum, Particle and Particle Systems Characterization, 23 (2006) 266-271.

Khan Z.S., Tokaruk W.A., Morris S.W., Oscillatory granular segregation in a long drum mixer, Europhysics Letters, 66 (2004) 212-218.

Klisiewicz P., Roberts J.A., Pohlman N.A., Segregation of titanium powder with polydisperse size distribution: Spectral and correlation analyses, Powder Technology, 272 (2015) 204-210.

Kuo H.P., Burbidge A.S., Knight P.C., Parker D.J., Adams M.J., Seville J.P.K., Non-equilibrium particle motion in the vicinity of a single blade, Powder Technology, 132 (2003) $1-9$.

Kuo H.P., Hsiao Y.C., Shih P.Y., A study of the axial segregation in a rotating drum using deformable particles, Powder Technology, 166 (2006a) 161-166.

Kuo H.P., Hsu R.C., Hsiao Y.C., Investigation of axial segregation in a rotating drum, Powder Technology, 153 (2005) 196-203.

Kuo H.P., Shih P.Y., Hsu R.C., Coupled axial-radial segregation in rotating drums with high fill levels, AIChE Journal, 52 (2006b) 2422-2427.

Maneval J.E., Hill K.M., Smith B.E, Caprihan A., Fukushima E., Effects of end wall friction in rotating cylinder granular flow experiments, Granular Matter, 7 (2005) 199-202.
Marigo M., Cairns D.L., Davies M., Ingram A., Stitt E.H., A numerical comparison of mixing efficiencies of solids in a cylindrical vessel subject to a range of motions, Powder Technology, 217 (2012) 540-547.

Marigo M., Stitt E.H., Discrete element method (DEM) for industrial applications: Comments on calibration and validation for the modelling of cylindrical pellets, KONA Powder and Particle Journal, 32 (2015) 236-252.

Nakagawa M., Axial segregation of granular flows in a horizontal rotating cylinder, Chemical Engineering Science, 49 (1994) 2540-2544.

Nedderman R.M., Laohakul C., The thickness of the shear zone of flowing granular materials, Powder Technology 25 (1980) 91-100.

Oshitani J., Ohnishi M., Yoshida M., Franks G.V., Kubo Y., Nakatsukasa S., Dry separation of particulate iron ore using density-segregation in a gas-solid fluidized bed, Advanced Powder Technology, 24 (2013) 554-559.

Oyama Y., Bull. Inst. Phys. Chem Res. (Tokyo), Rep. 5. 1939;18:600. (Oyama's work was reported by Weidenbaum $\mathrm{SS}$ in Advances in Chemical Engineering, Vol. 2, p.211, edited by Drew TB and Hoopes JW. New York: Academic, 1958.)

Sederman A.J., Gladden L.F., Mantle M.D., Application of magnetic resonance imaging techniques to particulate systems, Advanced Powder Technology, 18 (2007) 23-38.

Troiano M., Salatino P., Solimene R., Montagnaro F., Wall effects in entrained particle-laden flows: The role of particle stickiness on solid segregation and build-up of wall deposits, Powder Technology, 266 (2014) 282-291.

Turner J.L., Nakagawa M., Particle mixing in a nearly filled horizontal cylinder through phase inversion, Powder Technology, 113 (2000) 119-123.

Windows-Yule K., Parker D., Density-driven segregation in binary and ternary granular systems, KONA Powder and Particle Journal, 32 (2015) 163-175. 


\section{Author's short biography}

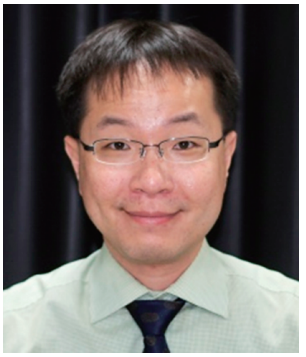

Hsiu-Po Kuo

Hsiu-Po Kuo received his B.Sc. degree and Ph.D. degree in Chemical Engineering from National Taiwan University, Taiwan in 1995 and from the University of Birmingham, UK in 2001, respectively. He joined Chang Gung University in 2002 and promoted as full Professor in 2012. He won the most-contributed editor title of Advanced Powder Technology journal from 2010 to 2013. He works closely with the Formosa Plastic Groups in Taiwan. He is interested in all particle technology related studies.

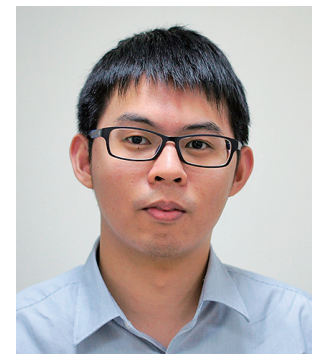

\section{Wei-Ting Tseng}

Mr. Wei-Ting Tseng received his bachelor in Department of Chemical and Materials Engineering, Chang Gung University, Taiwan in 2013. He is currently in his master program in Department of Chemical and Materials Engineering, Chang Gung University, Taiwan.

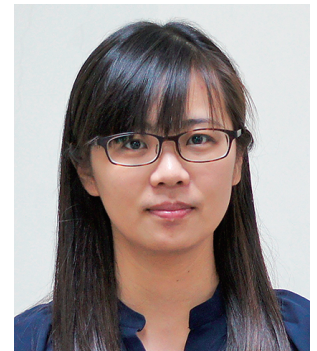

\section{An-Ni Huang}

Dr. An-Ni Huang received her bachelor degree from Yuan-Ze University, Taiwan in 2006 and doctor degree in Chemical and Materials Engineering from Chang Gung University, Taiwan in 2012. She is currently a post-doctoral researcher at Chang Gung University, Taiwan. Her research interests include CFD-DEM modeling of multiphase flows, mixing and ash management. 